\title{
Article
}

\section{Lessons from Grandfather}

\author{
Andrew Law and Ryan Wasserman *
}

Department of Philosophy, Western Washington University, Bellingham, WA 98225, USA; lawa@wwu.edu

* Correspondence: ryan.wasserman@wwu.edu

\begin{abstract}
Assume that, even with a time machine, Tim does not have the ability to travel to the past and kill Grandfather. Why would that be? And what are the implications for traditional debates about freedom? We argue that there are at least two satisfactory explanations for why Tim cannot kill Grandfather. First, if an agent's behavior at time $t$ is causally dependent on fact $F$, then the agent cannot perform an action (at $t$ ) that would require $F$ to have not obtained. Second, if an agent's behavior at time $t$ is causally dependent on fact $F$, then the agent cannot perform an action (at $t$ ) that would prevent $F$ from obtaining. These two explanations have distinct upshots for more traditional debates over freedom. The first implies that causal determinism is incompatible with the ability to do otherwise and also raises questions about the traditional arguments for the incompatibility of divine foreknowledge and the ability to do otherwise; the second does neither. However, both explanations imply that the Molinist account of divine providence renders agents unable to do otherwise, at least in certain circumstances.
\end{abstract}

Keywords: time travel; grandfather paradox; ability; freedom; fixity

Citation: Law, A.; Wasserman, R. Lessons from Grandfather. Philosophies 2022, 7, 11. https:// doi.org/10.3390/philosophies7010011

Academic Editor: Alasdair Richmond

Received: 4 November 2021 Accepted: 19 January 2022 Published: 25 January 2022

Publisher's Note: MDPI stays neutral with regard to jurisdictional claims in published maps and institutional affiliations.

Copyright: (C) 2022 by the authors. Licensee MDPI, Basel, Switzerland. This article is an open access article distributed under the terms and conditions of the Creative Commons Attribution (CC BY) license (https:// creativecommons.org/licenses/by/ $4.0 /)$.

\section{Introduction}

Tim despises Grandfather and desires nothing more than to kill him. But alas, he is too late: Grandfather died of natural causes when Tim was only a child. Tim is not so easily deterred though. He builds a time machine, travels back to a time before his grandparents first met, and approaches Grandfather on the street, gun in hand, hatred in his heart. ${ }^{1}$

Of course, we know that Tim will not kill Grandfather, since part of the story is that Grandfather died of natural causes. But can he do so? That is, does Tim have the power or ability to kill Grandfather? ${ }^{2}$

Many people are inclined to think not. Indeed, this thought plays a key role in one of the most common arguments against the possibility of time travel: if time travel were possible, then a person like Tim could retroactively kill his grandfather. But Tim cannot do that, so time travel is impossible.

We will not defend the traditional answer here, though we believe that such a defense is possible. ${ }^{3}$ Instead, we are interested in where this answer leads us. In particular, we will focus on two questions: (i) If Tim cannot kill Grandfather, then what is the best explanation for this fact? (ii) What, if anything, does this explanation teach us about other, more familiar debates about freedom? Regarding question (i), we will argue that there are at least two plausible explanations for why Tim cannot kill Grandfather. Regarding (ii), we will aim to show that both explanations render certain views about freedom problematic. But, before we get there, we will consider some less promising explanations for why Tim cannot kill Grandfather.

\section{You Cannot Do the Impossible}

The first explanation for Tim's inability is simple: Tim cannot kill Grandfather because doing so would be impossible. 
If this was the correct explanation for Tim's inability, then the Grandfather paradox would have nothing new to teach us about the topic of freedom. After all, our inability to do the impossible is something that most of us already take for granted. ${ }^{4}$

However, the current explanation is not correct-or at least not complete. First, note that the act-type in question- " "killing Grandfather" - is not in fact impossible. For example, many people could have killed Grandfather prior to Tim's arrival in the past. Indeed, if we assume that Grandfather lived long enough to overlap with Tim's childhood, then it was possible for Tim to kill Grandfather (in the traditional way, without traveling back in time). So, the explanation must be that it is impossible for Tim to kill Grandfather, and then only at the relevant time. However, once we make these changes, the explanation appears circular, since the claim that it is impossible for Tim to kill Grandfather (at the relevant time) seems equivalent to saying that Tim cannot (then) kill Grandfather.

In order to avoid the charge of circularity, one would need to provide an alternative understanding of "impossibility". For example, one could say that Tim is unable to kill Grandfather (at the relevant time) because his doing so would be physically impossible or metaphysically impossible or even logically impossible. On this way of looking at things, Tim cannot kill Grandfather (at the relevant time) for the same reason that he cannot accelerate past the speed of light, or drink water without $\mathrm{H}_{2} \mathrm{O}$, or prove modus ponens invalid-each of these things would be incompatible with the relevant laws (of physics, metaphysics, or logic).

This explanation would avoid the charge of circularity, but only at the cost of making implausible claims about physical, metaphysical, or logical possibility. After all, it does not seem impossible, in any of these senses, for Tim to kill Grandfather in the past. Consider a world where Grandfather miraculously rises from the dead in order to sire Father, who sires Tim, who travels back in time to kill Grandfather. Or consider a world where, right as Tim's bullet strikes his target, Grandfather fissions, leaving one living Grandfather and one dead (the living Grandfather going on to sire Tim's father, etc.). Or simply consider a world in which someone harvests Grandfather's genetic material shortly after his death and delivers it to Grandmother (so that she can sire Tim's father, etc.). These would all seem to be possible situations in which Tim kills Grandfather at the relevant time. ${ }^{5}$ So, Tim's inability cannot be explained by the impossibility of that act.

Of course, one might point out that the imagined possibilities are irrelevant to the case at hand. If there are no genetic harvesters waiting in the wings, then the physical possibility of such beings is irrelevant to the question of whether or not Tim can kill Grandfather. The same thing is true for resurrection and fission since (we can assume) those things are not possible in Tim's situation. So, one might try to explain Tim's inability to kill Grandfather (at the relevant time) by saying that it is physically (or metaphysically, or logically) impossible for him to do so given his actual circumstances. ${ }^{6}$ This explanation would not be obviously circular. Nor would it violate our intuitions about what is possible. But the challenge would be to say which features of Tim's circumstances are relevant and how they explain his inability to kill Grandfather. After all, to take a case inspired by David Lewis, it would be possible for a physical duplicate of Tim in physically identical surroundings to kill a physical duplicate of Grandfather [1]. So, the features of Tim's local environment cannot be what explains his inability. The question then remains: what is it about Tim's circumstances that render him unable to kill Grandfather? As we will see, there are several different ways of answering this question.

\section{You Cannot Do Anything Incompatible with the Past}

A second explanation for Tim's inability begins with the extremely intuitive idea that the past is "over and done with," "settled," or "fixed." Therefore, Tim's attempting to kill Grandfather in the past would be no more useful than his crying over spilt milk. Or more carefully, this explanation starts with the following principle: 
Fixity of the Past (FP): For any agent, $S$, action $X$, and time $t$, if it is true that, were $S$ to do $X$ at $t$, some fact about the past (relative to $t$ ) would have been different, then $S$ cannot do $X$ at $t^{7}$

Now suppose that Tim is considering stepping into his time machine in the year 2021 to travel back and kill Grandfather in 1921. Since Grandfather in fact survived 1921, Tim's plan would require a fact about the past (relative to 2021) to be different. FP therefore says-correctly - that Tim cannot travel to the past and kill Grandfather.

Moreover, this explanation would seem to have significant implications for various debates over freedom. First, FP is often a crucial ingredient in arguments for the incompatibility of freedom and causal determinism. If causal determinism is true, then all of our actions are entailed (and caused) by the past and the laws. So, if we were to do otherwise, either the past or the laws would have to have been different. But, according to FP, we cannot perform an action that would require the past to be different. And it would seem as if we likewise cannot perform an action that would require the laws to be different. So, causal determinism is incompatible with the freedom to do otherwise. ${ }^{8}$

Second, FP plays a central role in arguments for the incompatibility of freedom and divine foreknowledge. If there is an infallible God who knows and has always known everything we will ever do, then, if we were to do otherwise, some of God's past beliefs would have to have been different than what they actually are. But according to FP, we cannot perform an action that would require the past to be different. So, divine foreknowledge is incompatible with the freedom to do otherwise. ${ }^{9}$

Both of these arguments have generated an enormous literature. However, we will not be addressing either argument (in its current form), since FP is not a satisfactory explanation of Tim's inability to kill Grandfather. There are two problems with this account, one obvious and one less so.

The obvious problem is this: while FP implies that Tim cannot, in the year 2021, travel to the past and kill Grandfather, it does not imply that he cannot, in the year 1921, carry out his plan. That's because the fact that Grandfather survived 1921 is only a fact about the past "before" Tim travels back to that time. Once he exits his time machine, Grandfather's survival is no longer in the past, so FP gives us no reason to think that Tim cannot carry out his plans.

The less obvious problem is this: while Tim, in the year 2021, cannot travel to the past and kill Grandfather, it does seem as if he can travel to the past and do something more mundane-he could, for example, kick over a rock in the year 1921, even if the rock was not in fact kicked over at that time. Or, at the very least and at first glance, the claim that Tim cannot kill Grandfather is far more intuitive than the claim that he cannot kick over the rock. ${ }^{10}$ This, however, runs contrary to FP. The rock's not being kicked over in the year 1921 is just as much a part of the past, relative to 2021, as Grandfather's survival. That is, if Tim were to travel to the past and kick over the rock, a fact about the past (relative to the year 2021) would have to have been different. So, FP implies that, in the year 2021, Tim cannot even travel back and perform the simplest of actions (apart from those that he actually performs). This seems incorrect. Indeed, if time travel is possible, this constitutes a counterexample to FP. $^{11}$

These two problems together show, at the very least, that Grandfather's survival being in the past is not enough to explain Tim's inability to kill him. But they also suggest a different way of understanding the claim that the past is fixed. This brings us to our third explanation.

\section{You Cannot Do Anything Incompatible with Your Causal Past}

Return to the difference between Tim's traveling to the past to kill Grandfather and his traveling to the past to kick over a rock. While there may not be a temporal difference between the two-both Grandfather's survival and the rock's not being kicked are in the past-there is an important causal difference. Grandfather's survival is a cause (or a cause of a cause ... ) of Tim's existence and, hence, of his traveling to the past in an attempt to 
kill Grandfather; the rock's not being kicked over plays no such role. That is, while both Grandfather's survival and the rock's not being kicked over are part of the temporal past (relative to the year 2021), only the former is a part of Tim's causal past, where an agent's causal past includes all of those events that are causes (or causes of causes ... ) of the agent's present experiences and behavior. Given the foregoing shortcomings of FP, one might think that it is not the temporal past that is "settled" or "fixed" for agents, but the causal past instead. Under such a view, it is not the temporal relation per se between an agent and certain facts that matters for control; it is the causal relation instead.

One way to formalize this idea is as follows:

Fixity of the Causal Past (FCP): For any agent, $S$, action $X$, and time $t$, if it is true that, were $S$ to do $X$ at time $t$, some fact about $S$ 's causal past (relative to $t$ ) would have been different, then $S$ cannot do $X$ at $t .^{12}$

For non-time travelers, such as ourselves, the difference between FP and FCP might be of little significance (although we will return to this shortly). But for individuals like Tim, the difference could not be more crucial. Grandfather's survival is part of Tim's causal past both before and after he enters his time machine. So, FCP implies that Tim lacks the ability to kill Grandfather at both of those times. However, while the rock's not being kicked over may be part of the temporal past (before Tim enters his time machine), it is not (necessarily) a part of his causal history. ${ }^{13}$ So, FCP does not imply that he cannot kick over the rock. FCP is thus a more promising explanation of Tim's inability to kill Grandfather. ${ }^{14}$

FCP would also have significant implications for many debates over freedom. For instance, if causal determinism is true, then our causal pasts necessitate all of our behavior. Since FCP claims that our causal pasts are fixed in determining what we are free to do, FCP implies that causal determinism is incompatible with our being free to do otherwise. Or return to the issue of divine foreknowledge. Even if God's infallible beliefs are part of the temporal past, they are (arguably) not part of our causal pasts, in which case FCP does not imply that divine foreknowledge is incompatible with our being free to do otherwise. This would be a significant result, for it would imply that determinism undermines freedom in way that foreknowledge does not. ${ }^{15}$

While FCP is an improvement over FP, it still has a significant shortcoming, one involving a slightly different asymmetry. Suppose that Tim travels to the past and visits himself as an infant. Struck by his own cuteness, Adult Tim considers pinching Infant Tim on the cheek but ultimately decides against it. Intuitively, even though Tim does not pinch his infant self (or even attempt to), he could have. Or, at the very least, it is not obvious that he is unable to do so.

Once we admit of this asymmetry in Tim's abilities, FCP looks problematic. After all, the fact that Infant Tim was not pinched at the time in question would be a fact about Tim's causal past since it would directly concern his own earlier experiences. So, FCP implies that Tim cannot pinch his earlier self, any more than he can kill Grandfather. This seems incorrect.

Fortunately, there is a relatively simple way of getting around this problem.

\section{You Cannot Do Anything Incompatible with the Causal Past of Your Behavior}

The simple move is this: instead of holding fixed the agent's causal past in determining what they can do, we ought to hold fixed the causal past of the agent's behavior. Return to the difference between Tim's not killing Grandfather and his not pinching his infant self. The absence of each of these events may be part of Tim's causal past, but only the former absence is a cause (or a cause of a cause ... ) of Tim's traveling to the past and his other subsequent actions. Infant Tim's not being pinched might be a cause of some of Tim's behavior (e.g., it might be a cause of his not crying at that moment), but it does not play a causal role in his decision to travel back in time or his decision to refrain from pinching his younger self.

This suggests the following revision of FCP: 
Fixity of the Causal Past-Behavior (FCP-B): For any agent $S$, action $X$, and time $t$, if it is true that, were $S$ to do $X$ at $t$, some fact about the causal past of $S$ 's behavior at $t$ would have been different, then $S$ cannot do $X$ at $t$.

FCP-B respects the intuitive verdict in all of our cases so far. It implies that Tim cannot kill Grandfather, but it does not imply that Tim cannot kick over the rock or that he cannot pinch his earlier self. Moreover, it still delivers significant results for the debates over freedom: for similar reasons as those rehearsed above, it also seems to imply that causal determinism, but not necessarily divine foreknowledge, is incompatible with our being free to do otherwise.

However, there is one final problem to address. Consider a case of overdetermination. Suppose that, before stepping into his time machine, Tim draws up two qualitatively identical sets of plans for his time machine. He then travels back in time, tracks down his younger self, and passes off both sets of plans. Young Tim sees both sets simultaneously and, over time, uses that information to build a time machine. He then draws up two qualitatively identical sets of plans, enters into the time machine, and sets off to find his younger self ...

Now add a small wrinkle to the story: suppose that, just before Old Tim gave Young Tim both sets of plans, he considers destroying one set. (Perhaps he is worried that the second set could fall into the wrong hands.) Old Tim eventually decides against destroying either set, and passes on both sets of plans to Young Tim.

While Old Tim did not destroy a set of plans, it nonetheless seems as if he could have. He could not have destroyed both sets, of course, since he would then never be in a position to travel back in time with the plans to begin with. But destroying one set seems harmless, since each set is causally sufficient for Tim's actual journey. ${ }^{16}$

FCP-B implies the opposite. Since each set of plans is a cause of Tim's behavior (including his trip to the past), FCP-B implies that he cannot destroy either set. In order to avoid this result, we will have to make one final adjustment. Instead of holding fixed every cause of an agent's behavior, we should only hold fixed those causes on which the agent's behavior depends. Here, $x$ is causally dependent on $y$ just in case (i) $x$ would not have occurred (or been the case) if $y$ had not occurred, and (ii) this counterfactual holds at least in part because $y$ is a cause of $x$. In the case of overdetermination, the survival of each set of plans is a cause of Tim's journey to the past, but his journey to the past does not counterfactually depend on either set. If Tim were to destroy the second set, his younger self would still receive the first set, which is all that is required for Tim's journey to the past (as well as his writing down both sets of plans). So, by definition, his journey to the past does not causally depend on either set.

To capture this thought, we can (one last time!) revise our principle as follows:

Fixity of the Causal Past-Behavior* (FCP-B* ${ }^{*}$ : For any agent $S$, action $X$, and time $t$, if it is true that, were $S$ to do $X$ at $t$, some fact that $S$ 's behavior at time $t$ is (actually) causally dependent on would not have occurred, then $S$ cannot do $X$ at $t$.

We have finally arrived at a satisfactory explanation of Tim's inability to kill Grandfather. Like its predecessors, this principle has significant implications for freedom. Again, FCP-B* would seem to imply that causal determinism is incompatible with our being free to do otherwise, at least in those cases where our behavior is not causally overdetermined. Moreover, just as with FCP and FCP-B, our final principle does not imply that divine foreknowledge is incompatible with our being free to do otherwise. It is true that our behavior would counterfactually depend on God's past beliefs. But counterfactual dependence and causal dependence are two different things. Assuming that our behavior is not caused by God's past beliefs, FCP-B* does not apply to the case of divine foreknowledge.

These would be fascinating lessons from Grandfather. Unfortunately (or perhaps fortunately), concluding that FCP-B* is the correct explanation is too hasty. That's because there is a simpler and more restricted principle that can do the same work. ${ }^{17}$ 


\section{You Cannot Do Anything That Would Be Self-Undermining}

One common reason for thinking that Tim cannot retroactively kill Grandfather is that such an act would be, in some sense, self-defeating. ${ }^{18}$ After all, if Tim were to kill Grandfather, then Father would never be born, in which case Tim would never be born, in which case Tim would not go back to kill Grandfather. So, Tim's murder of Grandfather would be "self-undermining" in the sense that, were he to do it, Tim would not be there to kill Grandfather in the first place. Plausibly, no agent can perform an action of this kind, which would explain why Tim is unable to kill Grandfather.

There is something appealing about this rationale, but it needs to be made more precise. The rough characterization of a "self-undermining" act just given cannot be right. According to that characterization, Tim's killing Grandfather is a self-undermining act if the closest world where he kills Grandfather is a world in which he does not. But there are no (possible) worlds like that, so the counterfactual-if Tim were to kill Grandfather, then he would not-is trivially true, at best. At worst, the counterfactual is false since, as already noted, there seem to be (possible) worlds where Tim successfully kills Grandfather. Without a more plausible characterization of a "self-undermining" act, this explanation is incomplete.

Fortunately, our reflections on causation, behavior, and dependence point toward a better characterization. We have already noted that Tim's attempt to kill Grandfather is causally dependent on Grandfather's survival. So, Tim's attempt to kill Grandfather is an attempt to perform an action such that, were he to successfully perform it, some event that his attempt is causally dependent on would not have occurred. But Tim's attempt to kill Grandfather is more than that: his attempt, if successful, would prevent an event that his very attempt is causally dependent on. That is, there's not only a counterfactual relation between the success of his attempt and his attempt's causal history (namely, if he were to succeed, then an event that his attempt is causally dependent on would not have occurred), but a causal relation as well (namely, if he were to succeed, then he would prevent such an event).

With this in mind, one could hold that there is no difficulty in an agent performing an action such that, were she to perform it, some event that her behavior is causally dependent on would not have occurred. The difficulty only arises if the agent's action would cause the event to not occur. Or, more formally:

No Self-undermining Actions (NSA): For any agent $S$, action $X$, and time $t$, if it is true that, were $S$ to do $X$ at time $t, S$ would thereby prevent some fact that $S^{\prime}$ s behavior at time $t$ is (actually) causally dependent on, then $S$ cannot do $X$ at $t$.

Like FCP-B*, NSA respects the intuitive verdicts in our previous cases. If Tim were to kick over the rock, pinch his younger self, or destroy one set of plans, he would not thereby prevent some fact that his (actual) behavior is causally dependent on. Thus, NSA does not imply that Tim is unable to do those things.

However, unlike FCP-B*, NSA does not imply that causal determinism is incompatible with freedom. To illustrate, suppose that causal determinism is true and that Tim picks up his coffee cup at time t. If Tim had not picked up the cup at that time, then (given determinism) some event that his actual behavior causally depends on would have to have been different-perhaps a certain neuron that fired just prior to his picking up the cup would not have fired in that counterfactual scenario. ${ }^{19}$ But his refraining from picking up the coffee cup in that case would not have prevented the earlier firing of the neuron. More generally, doing otherwise in a deterministic world requires a certain counterfactual connection between our behavior and the events that our behavior is causally dependent on. But it does not require that, were we to do otherwise, we would thereby cause some of those events to be different. So, doing otherwise in a deterministic world does not violate NSA.

What about the issue of divine foreknowledge and freedom? Like FCP-B*, NSA does not imply that divine foreknowledge and freedom are incompatible. If we were to do otherwise than what we actually do, God would have had a different set of beliefs in the past. But, as already noted, our actual behavior is not causally dependent on God's past 
beliefs. Moreover, it is at least arguable that our doing otherwise would not have prevented God from holding his actual, earlier beliefs. ${ }^{20}$

While NSA fails to imply that freedom is incompatible with causal determinism or divine foreknowledge, it is less clear how significant this is. As we saw above, the principle of the Fixity of the Past (FP) is a driving force behind the standard arguments that causal determinism and divine foreknowledge are both incompatible with freedom. Even if one rejects FP (as we think one ought to), there is still some pressure to account for whatever it is that we find intuitive about this principle. For instance, suppose that Tim leaves his house very late and, thus, is sure to be tardy for the faculty meeting. Is he now able to arrive on time? Presumably not. But if we reject FP, then what accounts for Tim's inability in this case? Without an account, there is always the danger that whatever kernel of truth there is in FP will be enough to establish the incompatibility of freedom with causal determinism and foreknowledge.

This is one of the reasons principles like FCP and its variations are so significant: in addition to delivering intuitive results in various time travel cases (and not delivering unintuitive ones), they seem to capture the appeal of FP in ordinary contexts. If Tim were to arrive on time to the faculty meeting, it is not just that some fact about the temporal past would have been different, but, arguably, some fact about Tim's causal past, or the causal history of his behavior, would have been different as well. (Either he would not have left so late, or there would not have been so much traffic, etc.) That means FCP and its variations might be suitable replacements for FP-they may capture the intuitive idea behind that principle.

This is in stark contrast with the relation between NSA and FP. Whatever intuitive appeal FP has, it is not captured by NSA. If Tim were to arrive on time to the faculty meeting, he would not thereby prevent some fact that his actual behavior is causally dependent on, and so NSA does not imply that Tim cannot arrive on time. Any suitable replacement for FP ought to imply as much. Hence, those who are sympathetic to the standard arguments for the incompatibility of freedom and causal determinism or divine foreknowledge should not feel threatened by the truth of NSA whatsoever. Or another way to put the point: while there would seem to be little motivation for accepting both FCP (or some variation thereof) and FP, there is plenty of motivation for accepting both NSA and FP. If so, then the fact that NSA fails to imply that freedom is incompatible with causal determinism or foreknowledge is of little to no significance. NSA is simply orthogonal to such debates.

This might leave one wondering whether there are any significant implications of NSA. We believe that there is at least one, and it involves another theological example. "Molinism" or "Middle-knowledge theory" is a popular account of how God exercises providential control over the world (assuming that God exists). Roughly, it is comprised of (at least) three claims: (i) for any possible agent, $S$, and any possible circumstance, $C$, that $S$ might be in, there is a fact of the matter as to what $S$ would freely do in $C$; (ii) such facts, often called "counterfactuals of creaturely freedom," are contingent and independent of God's will; and (iii) God uses knowledge of such facts in determining which world to actualize. As a simplistic example, suppose God is deciding whom to place in the garden. Looking over all the possible creatures, and knowing what each creature would freely do, were they placed in the garden, God ranks Adam as the best overall choice with Ben a very close second. However, Adam is only ranked ahead of Ben because Adam would freely eat of the fruit, were he placed in the garden; if it were not the case that Adam would freely do so, then God would have ranked Ben over Adam. So, God places Adam in the garden and Adam freely eats of the fruit, God of course knowing that he would do so.

Is Adam able to refrain from eating the fruit? Not if NSA (or FCP-B ${ }^{*}$ ) is correct. Presumably, Adam's behavior in the garden is causally dependent both on God's decision to place him in the garden (or actualize a world where Adam is in the garden) and God's belief that Adam would freely eat the fruit, were Adam placed in the garden. So, according to FCP-B* , both God's decision and God's belief are fixed in assessing whether Adam could refrain from eating the fruit, which means that Adam cannot refrain. The same result 
holds under NSA. If Adam were to refrain from eating the fruit, he would have thereby prevented God from believing that, were Adam placed in the garden, he would freely eat the fruit (since that counterfactual of creaturely freedom would not be true). So, if Adam were to refrain from eating the fruit, he would thereby prevent a fact (or event) that his actual behavior is causally dependent on. So, NSA implies that Adam cannot refrain. ${ }^{21}$

What should the Molinist make of this? One option is to reject the starting assumption of this paper and insist that Tim can kill Grandfather. One could then reject our case for FCP-B* and NSA and insist that Adam could have refrained from eating the fruit (despite the fact that this would be a self-undermining act). In our view, a more promising option is to instead insist that an agent can freely perform an action even if the agent is not able to do otherwise- that Adam freely eats of the fruit even though he could not have refrained from doing so. ${ }^{22}$ Admittedly, the view that freedom does not require the ability to do otherwise is not a novel one, even in the context of Molinism ${ }^{23}$ or time travel. ${ }^{24}$ But what is noteworthy is that, if our starting assumption that Tim cannot kill Grandfather is correct, and if either FCP-B* or NSA is the correct explanation for that assumption, then Molinists must accept this conclusion. Many will deem that a cost for the Molinist view of providence.

\section{Conclusions}

Where has our starting assumption led us? First, if we are correct, then the right way to think about the fixity of the past is in terms of causation, rather than time. Given the prominent role the fixity of the past plays in many contemporary arguments regarding freedom, this is an important result. Second, regardless of whether FCP-B* or NSA is the correct explanation for Tim's inability to kill Grandfather, it appears that Molinist views of providential control limit the abilities of agents in interesting ways. Both of these claims, we suggest, are important lessons to take away from Grandfather. ${ }^{25}$

Author Contributions: Conceptualization, A.L. and R.W.; methodology, A.L. and R.W.; writingoriginal draft preparation, A.L. and R.W.; writing—review and editing, A.L. and R.W. All authors have read and agreed to the published version of the manuscript.

Funding: This research received no external funding.

Conflicts of Interest: The authors declare no conflict of interest.

\section{Notes}

We borrow this familiar story from David Lewis. See [1].

"Can" is notoriously context sensitive and does not always concern agential abilities. If murder were made legal, then Tim "could" kill Grandfather in the sense that his doing so would be compatible with the relevant laws. But this would not mean that Tim had the ability to kill Grandfather, any more than overturing an ordinance aginst transubstantiation would grant him the power to turn water into wine. Our focus throughout will be on abilities.

3 We here have in mind the kind of argument given by Kadri Vihvelin — see [2,3] for discussion. For potential replies, see [4,5]. Vihvelin's argument famously relies on the principle that "if someone would fail to do something, no matter how hard or how many times she tried, then she cannot do it." While we would endorse a version of this principle, it leaves the more basic question unanswered: why would Tim fail to kill Grandfather, no matter what he tried? Without answer to this question, we would not have an explanation of Tim's inability. (For one possible answer, see Chapter 4, Section 3 of [3].)

For some exceptions to this rule, see [6,7].

See [2,3] and, especially, [8] for more cases of this kind.

Thank you to Dan Howard-Snyder and Neal Tognazzini for pressing this point.

See [9] for the classic formulation, but also [10-12].

For a more detailed treatment of this argument, see [9].

For the classic introduction to this argument, see [13].

We are assuming that the rock's being kicked over need not affect Tim's life up until 2021 in any significant way-that there is not necessarily a "butterfly effect" in this case. This is not to say that the rock could not have had such an effect. But, if it did, then our intuitions would shift. In particular, if Tim's trip to the past causally depended on the rock not being kicked, then it would 
seem as if Tim cannot kick over the rock. For simplicity, we will assume that there are no "butterfly effects" in the following cases as well.

For more on the problems with FP, see [14-17].

Michael Rea employs a similar principle in [18]. See also [15,17].

For a counter to this claim, see [18]. Again, for the sake of simplicity, we will assume that there is no causal connection of this kind.

FCP would also respect Lewis's famous asymmetry between Tim and Tom [1] (p. 149). For discussion, see [19].

See $[15,17]$ for more on the relationship bewteen FCP and theological fatalism. On the more general point that causal determinism seems to threaten freedom in a way that foreknowledge does not, see [20] (p. 412), [21] (p. 89), and, especially, [22] (p. 1012). One of the authors would like to thank Justin Mooney for helping develop this point.

To be clear, we are not denying FCP-B*. On the contrary, at least one of the authors of this paper accepts FCP-B* Rather, the point is that one need not accept FCP-B* to account for Tim's inability to kill Grandfather, since the principle in the next section looks equally promising (at least as an explanation of Tim's inability to kill Grandfather). Thank you to Dennis Whitcomb for suggesting this clarification. See, e.g., [1] (p. 152), [2] (p. 315), and [3] (p. 72).

Here, we continue to assume the standard view that, given determinism, the closest worlds where we act otherwise are ones where both the laws and the past are different. We also set aside the issue of causal overdetermination.

However, see Section 5 of [23], where it is suggested that some of God's past beliefs are causally dependent on our future actions. We are assuming that God's decision to actualize a world where Adam is in the garden is a cause (or a cause of a cause ... ) of Adam's eating the fruit, and also that the relevant counterfactual of creaturely freedom is a cause of God's creative decision. Both of these claims could be challenged. Nonetheless, there is clearly a sense in which God's decision to actualize the relevant world explains (at least ancestrally) Adam's eating the fruit. So too, there is a natural sense in which God's creative decision is explained (in part) by the relevant counterfactual of creaturely freedom. And it would not be difficult to amend FCP-B* or NSA to focus on explanatory dependence rather than causal dependence. For simplicity, we will ignore these complications.

Molinists appear to be split on whether freedom requires the ability to do otherwise. Molinism's namesake, Luis de Molina, seems to accept that claim, writing: "the third type is middle knowledge, by which, in virtue of the most profound and inscrutable comprehension of each faculty of free choice, [God] saw in His own essence what each such faculty would do with its innate freedom were it to be placed in this or in that or, indeed, in infinitely many orders of things-even though it would really be able, if it so willed, to do the opposite ... " [24] (p. 52). However, some contemporary Molinists, such as William Craig [25], deny this claim.

The issue of whether freedom (in the sense required for moral responsibility) requires the ability to do otherwise has received a vast amount of attention ever since Harry Frankfurt's pivotal piece [26], and even in the context of Molinism. (See the back-and-forth between [27-29].) Several authors have used cases of time travel to motivate this thought. See [30,31] for two examples. For helpful discussion and feedback, we thank Taylor Cyr, Dan Howard-Snyder, Frances Howard-Snyder, Hud Hudson, Christian Lee, Justin Mooney, Neal Tognazzini, and Dennis Whitcomb.

\section{References}

1. Lewis, D. The Paradoxes of Time Travel. Am. Philos. Quarterly 1976, 13, 145-152.

2. Vihvelin, K. What time travelers cannot do. Philos. Stud. 1996, 81, 315-330. [CrossRef]

3. Wasserman, R. Paradoxes of Time Travel; Oxford University Press: Oxford, UK, 2018.

4. Kiourti, I. Killing Baby Suzy. Philosophia 2008, 139, 343-352. [CrossRef]

5. Hanley, R. Autoinfanticide Is No Biggie: The Reinstatement Reply to Vihvelin. Philosophies 2021, 6, 87. [CrossRef]

6. Spencer, J. Able to do the Impossible. Mind 2017, 126, 466-497. [CrossRef]

7. Effingham, N. Time Travel: Probability and Impossibility; Oxford University Press: Oxford, UK, 2020.

8. Carrol, J. Ways to Commit Autoinfanticide. J. Am. Philos. Associat. 2016, 2, 80-91. [CrossRef]

9. Fischer, J.M. The Metaphysics of Free Will; Blackwell: Oxford, UK, 1994.

10. van Inwagen, P. An Essay on Free Will; Oxford University Press: Oxford, UK, 1983.

11. Ginet, C. On Action; Cambridge University Press: Cambridge, UK, 1990.

12. Fischer, J.M. Freedom, Foreknowledge, and the Fixity of the Past. Philosophia 2011, 39, 461-474. [CrossRef]

13. Pike, N. Divine Omniscience and Voluntary Action. J. Philos. 1965, 74, 27-46. [CrossRef]

14. Swenson, P. Ability, Foreknowledge, and Explanatory Dependence. Australas. J. Philos. 2016, 94, 658-671. [CrossRef]

15. Law, A. The Dependence Response and Explanatory Loops. Faith Philos. 2020, 37, 294-307. [CrossRef]

16. Law, A. From the Fixity of the Past to the Fixity of the Independent. Philos. Stud. 2021, 178, 1301-1314. [CrossRef]

17. Wasserman, R. The Independence Solution to the Problem of Theological Fatalism. Philos. Phenomenol. Res. 2020. [CrossRef]

18. Rea, M. Time Travelers are not Free. J. Philos. 2015, 112, 266-279. [CrossRef]

19. Wasserman, R. Time Travel, Ability, and Arguments by Analogy. Thought 2017, 6, 17-23. [CrossRef] 
20. Fischer, J.M.; Tognazzini, N.A. The Physiognomy of Responsibility. Philos. Phenomenol. Res. 2011, 82, 381-417. [CrossRef]

21. Byerly, T.R. Infallible Divine Foreknowledge Cannot Uniquely Threaten Human Freedom, but its Mechanics Might. Eur. J. Philos. Relig. 2012, 4, 73-94. [CrossRef]

22. Law, A.; Tognazzini, N.A. Free Will and Two Local Determinisms. Erkenntnis 2019, 84, 1011-1023. [CrossRef]

23. Wasserman, R. Freedom, Foreknowledge, and Dependence. Noûs 2021, 55, 603-622. [CrossRef]

24. Molina, L. On Divine Foreknowledge: Part IV of the Concordia; Freddoso, F., Ed.; Cornell University Press: Ithaca, NY, USA, 1988.

25. Craig, W.L. Response to Gregory A. Boyd. In Four Views on Divine Providence; Jowers, D., Ed.; Zondervan: Grand Rapids, MI, USA, 2011; pp. 224-230.

26. Frankfurt, H. Alternate Possibilities and Moral Responsibility. J. Philos. 1969, 66, 829-839. [CrossRef]

27. Bergmann, M. Molinist Frankfurt-style Counterexamples and the Free Will Defense. Faith Philos. 2002, 19, 462-478. [CrossRef]

28. Flint, T. On Behalf of the PAP-ists: A Reply to Bergmann. Faith Philos. 2002, 19, 479-484. [CrossRef]

29. Bergmann, M. Agent Causation and Responsibility: A Reply to Flint. Faith Philos. 2003, 20, 229-235. [CrossRef]

30. Spencer, J. What Time Travelers Cannot Do (But Are Responsible for Anyways). Philos. Stud. 2013, 166, 149-162. [CrossRef]

31. Tognazzini, N.A. Free Will and Time Travel. In The Routledge Companion to Free Will; Timpe, K., Griffith, M., Levy, N., Eds.; Routledge: New York, NY, USA, 2016; pp. 658-671. 